\title{
WEBSITE JUAL BELI ONLINE SEBAGAI SARANA BERKEMBANGNYA KOPERASI PRIMASOKA BANTARSOKA
}

\author{
Tyas Pratama Puja kusuma \\ Universitas Amikom Purwokerto \\ tyaspratama@amikompurwokerto.ac.id
}

\begin{abstract}
Primasoka Bantarsoka Cooperative is a cooperative that sells and buys basic necessities for residents of Griya Satria Bantarsoka Housing in particular and local residents in general. This cooperative provides residents' needs from basic necessities to secondary goods needed by residents. Primasoka Cooperative was formed on September 10, 2020 with 30 members. The initial purpose of the formation of this cooperative was to make it easier for people to get basic food items during the COVID-19 pandemic as it is now and to provide a platform for residents who want to be entrepreneurs. Cooperative members join the Whats app group to find out what merchandise is being sold. The solutions offered to solve the problems that exist in the Primasoka Cooperative are: (1) Changing the marketing model from using whats app groups to using buying and selling websites so that the marketing reach is wider; (2) Provide training on the use of buying and selling websites to management and cooperative members
\end{abstract}

Keywords: cooperative; sell; buy; online

\begin{abstract}
Abstrak
Koperasi Primasoka Bantarsoka adalah koperasi jual beli kebutuhan bahan pokok warga Perumahan Griya Satria Bantarsoka khususnya dan warga sekitar pada umumnya. Koperasi ini menyediakan kebutuhan warga dari sembako hingga barang-barang sekunder yang dibutuhkan warga. Koperasi Primasoka dibentuk pada tanggal 10 September 2020 yang beranggotakan 30 orang. Tujuan awal dibentuknya koperasi ini adalah untuk memberi kemudahan masyarakat mendapatkan bahan pokok makanan di saat pandemi covid 19 seperti sekarang ini dan memberikan wadah bagi warga yang ingin berwirausaha. Anggota koperasi bergabung di grup Whats app untuk dapat mengetahui barang dagangan apa saja yang dijual. Solusi yang ditawarkan untuk menyelesaikan permasalahan yang ada di Koperasi Primasoka adalah: (1) Mengubah model pemasaran dari menggunakan grup whats app berubah menggunakan website jual beli agar jangkauan pemasaran lebih luas; (2) Memberikan pelatihan penggunaan website jual beli kepada pengurus dan anggota koperasi
\end{abstract}

Kata Kunci: koperasi; jual; beli; online

Submitted: 2021-09-10

Revised: 2021-10-26

Accepted: 2021-10-31

\section{Pendahuluan}

Koperasi adalah badan usaha yang mengorganisir pemanfaatan dan pendayagunaan sumber daya ekonomi para anggotanya atas dasar prinsip-prinsip koperasi dan kaidah usaha ekonomi untuk meningkatkan taraf hidup anggota pada khususnya dan masyarakat daerah kerja pada umumnya (Rudianto,2010:3). Koperasi adalah organisasi dari orang-orang yang berhimpun secara sukarela untuk memenuhi kebutuhan dan ekonomi, sosial dan budaya secara bersama-sama melalui kegiatan usaha yang dimiliki dan dikendalikan secara demokratis (Hendar,2010:2).

Dari pengertian diatas Penulis menyimpulkan bahwa Koperasi adalah perkumpul suatu organisasi yang memanfaatkan sumber daya ekonomi untuk para anggotanya maupun masyarakat untuk memenuhi kebutuhan melalui transkasi di koperasi. Koperasi Primasoka Bantarsoka adalah koperasi jual beli kebutuhan bahan pokok warga Perumahan Griya Satria Bantarsoka khususnya dan warga sekitar pada umumnya. Koperasi ini menyediakan kebutuhan warga dari sembako hingga barang-barang sekunder yang dibutuhkan warga. Koperasi Primasoka dibentuk pada tanggal 10 September 2020 dengan jumlah anggota 30 orang. Tujuan awal dibentuknya koperasi ini adalah untuk memberi kemudahan masyarakat mendapatkan bahan pokok makanan di saat pandemi covid 19 seperti sekarang ini dan memberikan wadah bagi warga yang ingin berwirausaha. Cara bergabung menjadi anggota Koperasi Primasoka yaitu dengan membayar uang pendaftaran sebesar Rp. 200.000,00 uang tersebut nantinya digunakan sebagai modal usaha. Anggota koperasi bergabung di grup Whats app untuk dapat mengetahui barang dagangan apa 
saja yang tersedia di koperasi. Pemesanan belanjaan melalui grup whats app lalu barang akan diantar sesuai tujuan oleh pengurus koperasi.

Keuntungan menjadi anggota koperasi adalah natinya diakhir tahun anggota mendapatkan SHU atau Sisa Hasil Usaha dari koperasi tersebut dengan sistem bagi hasil. Karena koperasi ini baru saja dibentuk, maka belum banyak masyarakat yang mengetahui keberadaannya. Modal usaha yang dimiliki juga masih sangat minim, untuk itu, penulis berinisiatif membuat website jual beli yang dapat digunakan sebagai media untuk mengembangkan usaha koperasi. Dengan adanya website jual beli maka jangkauang anggota koperasi lebih luas sehingga koperasi dapat dengan pesat berkembang. Keuntungsn lainnya yang didapat dengan adanya website ini adalah anggota dapat mengetahui berapa keuntungannya selama berbelanja di koperasi. Selain itu, dengan sistem yang telah terkomputerisasi akan memudahkan pengurus koperasi dalam mengelola pembukuan dan laporan keuangan koperasi. adalah:

Solusi yang ditawarkan untuk menyelesaikan permasalahan yang ada di Koperasi Primasoka

1. Mengubah model pemasaran dari menggunakan grup whats app berubah menggunakan website jual beli agar jangkauan pemasaran lebih luas.

2. Memberikan pelatihan penggunaan website jual beli kepada pengurus dan anggota koperasi.

\section{Metode}

Metode yang digunakan dalam pelaksanaan kegiatan Pengabdian Amikom Mitra Masyarakat ini adalah dengan memberikan sosialisasi dan pelatihan. Adapun tahapan pelaksanaannya adalah dengan melakukan persiapan terlebih dahulu. Dalam tahap persiapan dilakukan dengan melakukan kerjasama dengan pengurus Koperasi Primasoka dalam pembuatan website jual beli. Kemudian melakukan wawancara dengan pengurus Koperasi guna memperoleh data-data yang diperlukan dalam pelaksanaan program. Pelaksanaan kegiatan merupakan realisasi perencanaan program, yaitu dengan memberikan pelatihan penggunaan website jual beli online. Partisipasi mitra dalam program ini adalah ikut serta menggunakan website jual beli online. Evaluasi pelaksanaan program dilaksanakan guna mengetahui keberhasilan program. Evaluasi dilakukan dengan melihat langsung jumlah pengguna website jual beli. Jika hasil nya masih jauh dari yang diharapkan maka akan diberikan sosialisasi kembali. Diharapkan program ini dapat bermanfaat untuk meningkatkan modal usaha koperasi Primasoka.

\section{Hasil dan Pembahasan}

Pelaksanaan kegiatan sosialisasi dan pelatihan penggunaan website jual beli online pada Pengabdian Amikom Mitra Masyarakat ini dilaksanakan dengan cara daring menggunakan media zoom cloud meetings karena masih adanya pandemic COVID 19. Gambar 1 menunjukan kegiatan sosialisasi dan pelatihan menggunakan media zoom cloud meetings. Kegiatan dihadiri oleh anggota Koperasi Primasoka, jumlah peserta yang mengikuti zoom meetings sebanyak 30 orang.

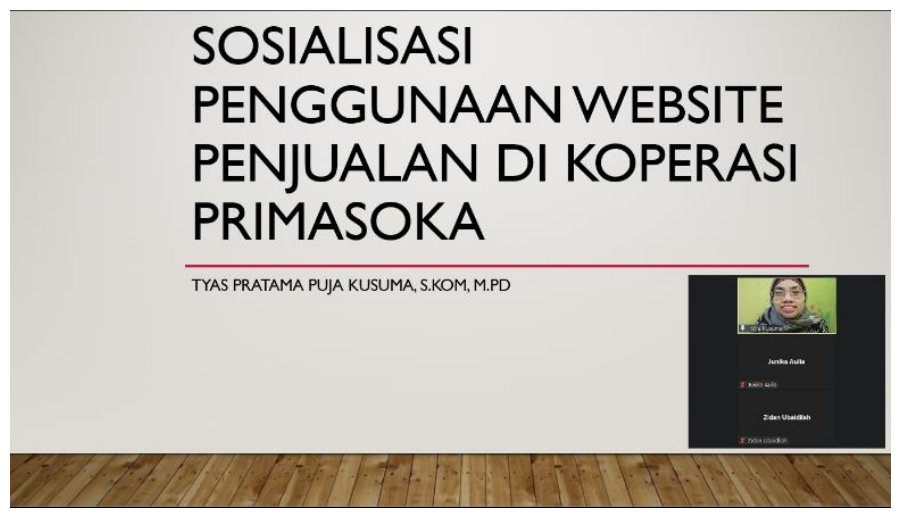

Gambar 1. Pelaksanaan sosialisasi menggunkan zoom cloud meetings. 
Materi yang disampaikan dalam sosialisasi adalah bagaimana cara penggunaan website jual beli di Koperasi Primasoka. Anggota koperasi harus mendaftar terlebih dahulu pada website agar dapat berbelanja menggunakan website jual beli koperasi Primasoka. Kemudiaan setelah login, anggota dapat berbelanja dan melihat detail transaksi yang telah dilakukan.

Website berisi menu daftar produk yang dijual di koperasi. Menu Detail produk berisi tentang informasi produk dari harga, berat dan jenis produk. Menu keranjang belanja digunakan untuk melihat daftar barang apa saja yang akan dibeli. Menu daftar untuk mendaftar sebagai anggota. Menu login bagi anggota untuk masuk sebagai pembeli dan di sana anggota juga dapat melihat SHU. Menu kontak digunakan untuk menghubungi petugas koperasi. Menu FaQ untuk tanya jawab seputar keanggotaan koperasi. Gambar 2 merupakan tampilan home website jual beli yang akan digunakan oleh anggota koperasi Primasoka.
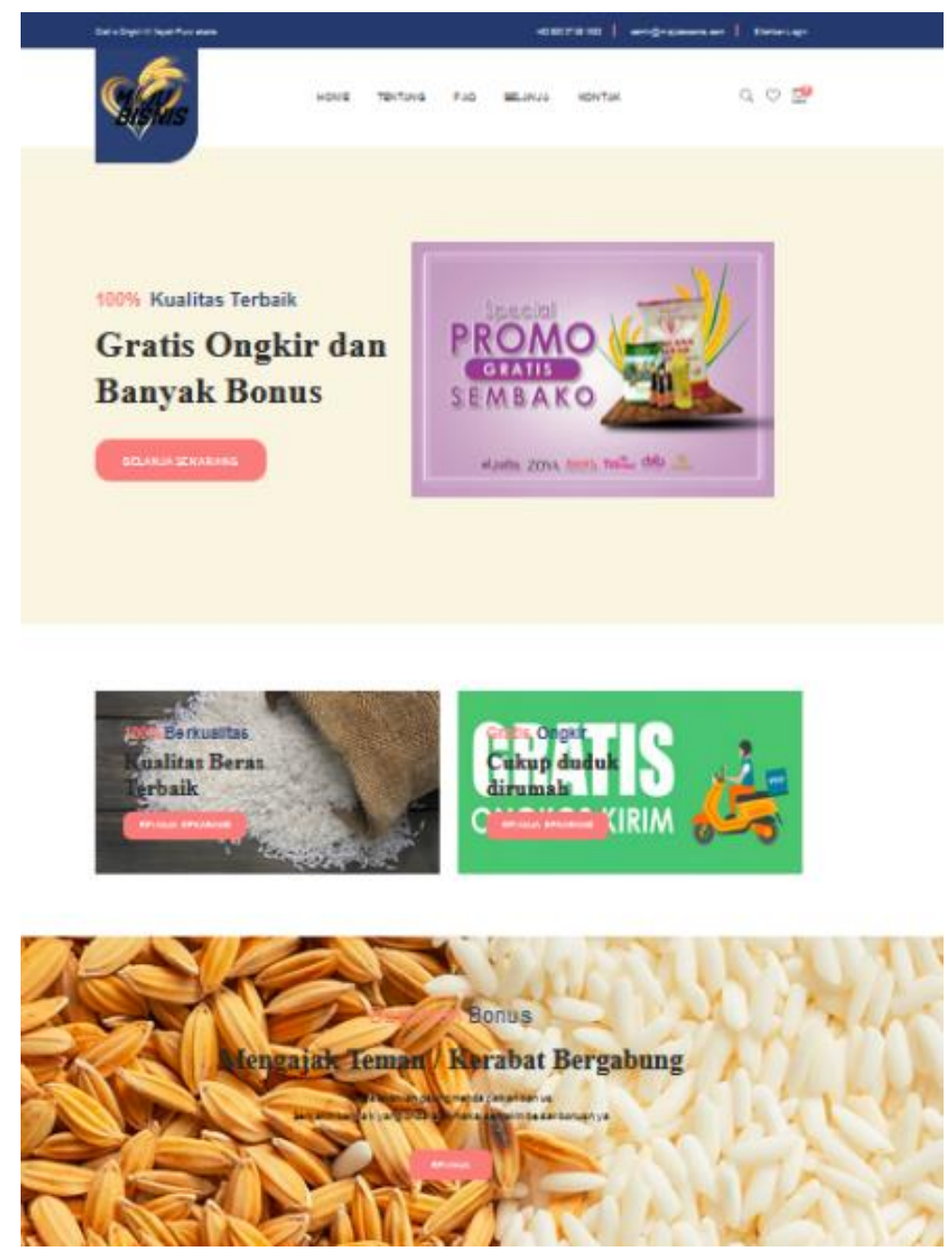

Gambar 2. Tampilan Home Website Jual Beli Koperasi Primasoka

Setelah dilaksanakan sosialisasi, dilakukan evaluasi terhadap penggunaan website. Evaluasi dilakukan dengan cara melihat traffic pengunjung website. Gambar 3 adalah tampilan web analis yang menunjukan jumlah pengunjung website dalam satu bulan. Dalam kurun waktu satu bulan setelah dilaksanakannya sosialisai, website telah dikunjungi sebanyak 330 kali. 
Worth \& Traffic Estimate of majubisnis.com

Estimated numbers for majubisnis.com

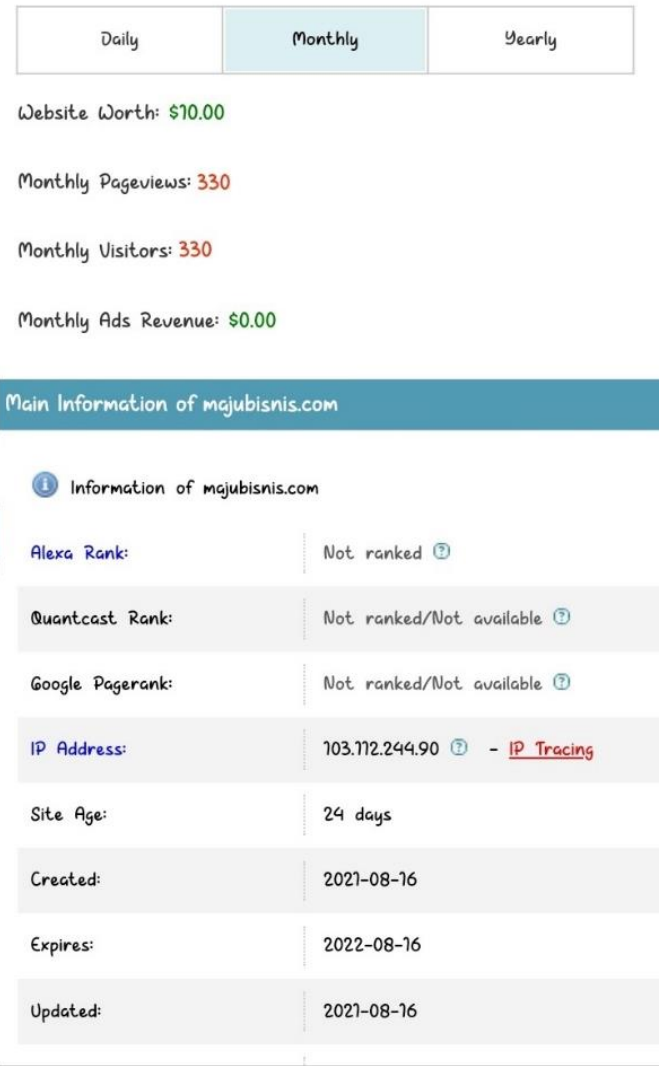

Gambar 3. Web Analis Pengunjung

Transaksi jual beli Koperasi Primasoka mengalami peningkatan dari sebelum dan sesudah penggunaan website. Dengan adanya website, peningkatan yang terjadi tidak hanya pada transaksi jual beli tetapi juga peningkatan pada jumlah anggota koperasi. Tabel 1 menunjukkan adanya peningkatan tersebut.

Tabel 1. Perbandingan sebelum dan sesudah adanya website

\begin{tabular}{llll}
\hline No & Keterangan & Juni & Juli \\
\hline 1 & Total Jumlah Transaksi & Rp. 2.780.000 & Rp. 2.880.000 \\
2 & Jumlah Member & 30 & 34 \\
3 & Jumlah barang terjual perbulan & 233 & 235 \\
4 & Persentase barang terjual Per-hari & $13,33 \%$ & $14,2 \%$ \\
5 & Jumlah Barang Retur/Kerugian & 0 & 0 \\
& Total & & \\
\hline
\end{tabular}

\section{Kesimpulan}

Dari hasil dan pembahasan di atas, dapat disimpulkan bahwa website jual beli berdampak positif terhadap kelangsungan koperasi Primasoka. Dengan adanya website tersebut transaksi jual beli di koperasi terjadi peningkatan, dengan demikian keuntungan yang diperoleh koperasi juga akan semakin besar. Selain itu juga, dengan adanya sosialisasi anggota koperasi menjadi bertambah. 


\section{Daftar Pustaka}

Agustina Lela dan Parjonoi, 2017. Pengaruh Suasana Toko dan Keanekaragaman Produk Terhadap Kepuasan Pembeli pada Konsumen Toserba Maya di Kec.Randublatung Kab. Blora. "Jurnal Pendidikan Tata Niaga (JPTN) ", ISSN: 2337-6708 Vol. 01 No.01: 39-43.

Fathurrahman, 2014. Membuat Website Mudah dan Praktis dengan Weeble, Jakarta: Penerbit PT Elex Media Komputindo.

Fatkhudin, Aslam, 2016. Sistem Informasi Penjualan dan Pembelian pada Toko Elektronik Lubada Jaya Kajen dengan Menggunakan Java. Pekalongan."Jurnal DIGITAL", ISSN: 2088-589X Vol.6 No.1 : 23-36.

Hariyanto Dicky, 2016. Rancang Bangun Sistem Informasi Pembelian dan Penjualan Barang Berbasis Website. "Jurnal dari SWABUMI ", ISSN: 2355-990, Vol. IV No. 2: 152-166.

Hartini Dwi and Sarjono, 2016. Analisis dan Perancangan Sistem Informasi Penjualan pada PT. Jaya Mandiri Strategic. Jambi. "Jurnal Manajemen Sistem Informasi", ISSN : 2540-8011 Vol.1 No. $1: 30-34$.

Hasyim Nurlaila, Nur Aeni Hidayah, Sarwoto Wijoyo Latisuro, 2014. Rancang Bangun Sistem Informasi Koperasi Berbasis Web pada Koperasi Warga Baru MTS N 17. Jakarta. "Jurnal dari Sistem Informasi", ISSN 1979-0767. 7(2): 1-11.

Hayuningtyas Ratih Yulia, 2015. Rancang Bangun Sistem Informasi Penjualan Tas pada Toko Lokalop. "Jurnal dari Sistem Informasi STMIK antar Bangsa", ISSN 2089- 8711 Vol. IV NO.2: 160-167.

Hendar, 2010. Manajemen Perusahaan Koperasi. Jakarta: Penerbit Erlangga.

Maulana Kiki Rizki and Bunyamin, 2015. Rancang Bangun Aplikasi Sistem Informasi Penjualan dan Stok Barang di Toko Widari Garut. "Jurnal Algoritma", ISSN: 2302-7339 Vol. 12 No. 1: 1-6.

Mega, Mahar, 2013. Manajemen Pemasaran. Yogyakarta: CAPS (Center of Academic Publishing Service).

Nugroho, Bunafit, 2013, Membuat Aplikasi WEB Penjualan Pembelian dengan PHP, MySQL dan Dreamweaver. Yogyakarta: Penerbit PT. Alif Media.

Raharjo, Budi, 2015. Belajar Otodidak MySQL. Bandung: penerbit informatika Bandung.

Raharjo, Budi, 2016. Pemrograman Web (HTML, PHP, \& MySQL) edisi ketiga. Bandung: penerbit Modula.

Riyono and Gigih Erlik Budiharja, 2016. Pengaruh Kualitas Produk, harga, Promosi dan Brand Image terhadap Keputusan Pembelian Produk di Kota Pati. "Jurnal Stie Semarang", ISSN: 2252-826 Vol 8 No 2: 92-121.

Rudianto, 2010. Akuntansi Koperasi Konsep dan Teknik Penyusunan Laporan Keuangan Edisi Kedua. Jakarta: Penerbit Erlangga.

Rumanta, 2013. Perancangan Sistem Informasi Pembelian dan Penjualan pada Oka Putra Motor Pacitan. "Jurnal Seruni", ISSN: 2302-1136 Vol 2 No 1: 44-49.

Safaat Nazruddin H, 2015. Rancang Bangun Aplikasi Multiplatform, Bandung: Penerbit Informatika Bandung.

Sandi, Mulyana, 2014. Bikin Website dengan Aplikasi-aplikasi Gratis, Yogyakarta: Penerbit PT. Buku Seru.

Supardi Yuniar, 2015. Mudah dan Cepat Membuat Skripsi dengan VB 2012, Jakarta: Penerbit PT Elex Media Komputindo.

Tim EMS, 2014. Teori dan Praktek PHP-MySQL untuk Pemula, Jakarta: Penerbit PT. Elex Media Komputindo. 
BERNAS:

Jurnal Pengabdian Kepada Masyarakat

[Vol. 2 No 4, 2021, pp. 1016-1021]

1021

Wahana Komputer,2013. Mobile Web Devolopment with Adobe Dreamweaver CS6. Semarang: Penerbit C.V ANDI Offset.

Zulfiandri, Sarip Hidayatuloh and Mochammad Anas, 2014. Rancang Bangun Aplikasi Poliklinik Gigi. "Prosiding Seminar Ilmiah Nasional Komputer dan Sistem Intelijen", ISSN: 2302-3740, Vol. 8: $472-482$. 